\title{
Antioxidant activities of kombucha prepared from three different substrates and changes in content of probiotics during storage
}

\author{
Caili FU ${ }^{1}$, Fen YAN ${ }^{1}$, Zeli CAO ${ }^{1}$, Fanying XIE ${ }^{1}$, Juan $\mathrm{LIN}^{1 *}$
}

\begin{abstract}
Kombucha is a health-promoting fermented beverage worldwide. The present study compared the free-radical scavenging abilities and total reducing power (TRP) of kombucha prepared from low-cost green tea (LGTK), black tea (BTK), and tea powder (TPK). LGTK had the highest scavenging abilities against 2,2-diphenyl-1-picrylhydrazyl (DPPH), superoxide anion and hydroxyl radicals, while BTK showed the highest TRP. Changes in content of probiotics in LGTK were investigated during storage as well. The number of acetic acid bacteria decreased moderately up to 10 days of storage. The number of lactic acid bacteria (LAB) decreased significantly, and their survival rate was only $0.98 \%$ at the $8^{\text {th }}$ day of storage.
\end{abstract}

Keywords: kombucha; antioxidant activities; probiotics; storage.

\section{Introduction}

Kombucha, a popular beverage consumed throughout the world as a medicinal health-promoting drink, is typically made by fermenting sugared tea with a symbiosis of yeast species, fungi, and acetic acid bacteria at ambient temperature for about 7-14 days. This beverage is composed of some probiotics such as acetic acid bacteria and lactic acid bacteria in addition to tea polyphenols, sugars, organic acids, ethanol, water soluble vitamins, and a variety of micronutrients produced during fermentation (Chen \& Liu, 2000; Greenwalt et al., 2000; Malbasa et al., 2008). The main acetic acid bacteria species found in kombucha were identified as Acetobacter xylinoides, A. pasteurianus, A.xylinum, A. aceti, and Bacterium gluconicum. While yeasts species isolated from kombucha mainly included Brettanomyces bruxellensis, B. lambicus, B. custersii, Kloeckera apiculata, Saccharomycodes ludwigii, Schizosaccharomyces pombe, Saccharomyces cerevisiae, Zygosaccharomyces bailii, Candida, and Pichia species (Chen \& Liu, 2000; Greenwalt et al., 2000; Malbasa et al., 2008; Chu \& Chen, 2006; Malbasa et al., 2011). Previous studies from our laboratory have shown that kombucha prepared by mixed-culture fermentation with pure strains had a distinctive flavor and short fermentation period (Ma et al., 2008; Xie, 2011). Numerous health benefits have been attributed to the consumption of this beverage, including: it stimulates the immune system, aids digestion, protects against cancer and cardiovascular diseases, prevents microbial infections; it is also known for its hypoglycemic and antilipidemic properties, free-radical scavenging activities, among others (Chen \& Liu, 2000; Greenwalt et al., 2000; Malbasa et al., 2008; Chu \& Chen, 2006; Malbasa et al., 2011; Aloulou et al., 2012; Ilicic et al., 2012; Yang et al., 2009; Greenwalt et al., 1998).

In addition to the health-promoting effects, changes in chemical and microbial components and bioactivities during tea fungus fermentation have also been widely investigated by researchers. Chen \& Liu found changes in major components and microbes in kombucha prepared from nine different sources during a prolonged fermentation of up to 60 days (Chen \& Liu, 2000). Jayabalan and his partner reported changes in the content of organic acids and tea polyphenols, $\mathrm{pH}$, protein, and microbial content in kombucha prepared from green tea, black tea, and tea manufacture waste during tea fungus fermentation (Jayabalan et al., 2007). It has been found that the concentration of acetic acid reached maximum on the $15^{\text {th }}$ day (green tea kombucha), while glucuronic acid concentration reached maximum on $12^{\text {th }}$ day (black tea kombucha) of fermentation, respectively. In a later study, these authors also analyzed the changes in free-radical scavenging ability of kombucha during fermentation (Jayabalan et al., 2008a). Moreover, there is a interesting report that lactic acid bacteria obtained from kefir can increase the productivity of bacteria in kombucha to higheffectively get d-saccharic acid 1, 4 lactone (Yang et al., 2010). However, research on the changes in content of probiotics during kombucha storage is rare.

The present study aims to compare the scavenging abilities against 2,2-diphenyl-1-picrylhydrazyl (DPPH), superoxide anions and hydroxyl radical, and total reducing power of kombucha prepared from low-cost green tea (LGTK), black tea (BTK), and tea powder (TPK), in addition to investigating the changes in the content of probiotics in LGTK during storage.

\section{Materials and Methods}

\subsection{Preparation of fermented tea}

Kombucha were prepared using low-cost green tea, black tea, and tea powder purchased from Damin Food (zhangzhou) Co., Ltd (Fujian, China). Briefly, 3.0 g of black tea, low-cost green tea, and tea powder, respectively, were steeped in $400 \mathrm{~mL}$ of boiling water and for $20 \mathrm{~min}$. The infusions were then filtered using filter paper and sucrose (5\%) was subsequently dissolved in the resulting clear filtrate. Subsequently, $200 \mathrm{~mL}$ of sugared 
tea filtrates were poured into a $500 \mathrm{~mL}$ Erlenmeyer flask, followed by sterilization at $115^{\circ} \mathrm{C}$ for $15 \mathrm{~min}$. After cooling to room temperature, the Erlenmeyer flask was inoculated with $5 \%$ culture, obtained from the culture collection of College of Bioscience \& Biotechnology, Fuzhou University, which was composed of Saccharomyces cerevisiae Meyen ex Hansen $\left(10^{8} \mathrm{CFU} / \mathrm{mL}\right)$, Gluconacetobacter sp. $\left(10^{8} \mathrm{CFU} / \mathrm{mL}\right.$, and Lactobacillus plantarum $\left(10^{8} \mathrm{CFU} / \mathrm{mL}\right)$, with the ratio of 1:1:1 and reported to be optimal strains for kombucha fermentation (Ma et al., 2008; Xie, 2011). The Erlenmeyer flask was carefully covered, and fermentation was performed at $30^{\circ} \mathrm{C}$ with shaking $(100 \mathrm{rpm})$ for $90 \mathrm{~h}$. The fermented tea was centrifuged at 10,000 rpm for $10 \mathrm{~min}$, and antioxidant activity was determined (Marques et al., 2012; Vissotto et al., 2013; Li et al., 2012). All analyses were carried out in duplicate.

\subsection{2,2-diphenyl-1-picrylhydrazyl (DPPH) free radical- scavenging ability}

2,2-diphenyl-1-picrylhydrazyl (DPPH) free radicalscavenging ability of kombucha prepared from low-cost green tea (LGTK), black tea (BTK), and tea powder (TPK) was measured according to the method described by Marques with some modifications (Marques et al., 2012). $2 \mathrm{~mL}$ of 160 -folds diluted kombucha samples were mixed with $2 \mathrm{~mL}$ of $0.1 \mathrm{mmol} / \mathrm{L}$ DPPH methanolic solution. The mixture was shaken vigorously and allowed to stand in the dark for $20 \mathrm{~min}$, after which the absorbance was measured at $517 \mathrm{~nm}$ using a spectrophotometer.

\subsection{Hydroxyl radicals-scavenging activity}

Briefly, $1 \mathrm{~mL}$ of $0.75 \mathrm{mmol} / \mathrm{L}$ 1, 10-phenanthroline solution, $2 \mathrm{~mL}$ of phosphate buffer saline $(0.15 \mathrm{~mol} / \mathrm{L}, \mathrm{pH}=7.49)$, and $1 \mathrm{~mL}$ of kombucha sample solutions with different diluted folds (20 folds for LGTK, 5 folds for BTK, and 10 folds for TPK, respectively) were added into the test tubes. An aliquot of $1 \mathrm{~mL}$ of $0.75 \mathrm{mmol} / \mathrm{L} \mathrm{FeSO}_{4}$ solution was then pipetted into the mixture. The reaction was initiated by adding $1.0 \mathrm{~mL}$ of $0.01 \%$ $\mathrm{H}_{2} \mathrm{O}_{2}$ solution. After incubation at $37^{\circ} \mathrm{C}$ in a water bath for $60 \mathrm{~min}$, the absorbance of the reaction mixture was measured at $536 \mathrm{~nm}$ against reagent blank (Vissotto et al., 2013).

\subsection{Superoxide radical-scavenging activity}

The superoxide radical-scavenging activity was measured at $25^{\circ} \mathrm{C}$ as previously described (Li et al., 2012). An aliquot of $24 \mu \mathrm{L}$ of $25 \mathrm{mmol} / \mathrm{L}$ pyrogallol solution was added to a tube containing $100 \mu \mathrm{L}$ kombucha samples and $4.50 \mathrm{~mL}$ of Tris-HClEDTA buffer (0.05 M, pH 8.20). The optical density (OD) was measured at $325 \mathrm{~nm}$ for 30 min every 30 s against a blank using a spectrophotometer.

\subsection{Total reducing power}

The total reducing power was measured according to the method described by Yen \& Chen (1995). Briefly, $2.0 \mathrm{~mL}$ of the sample solution with different diluted folds (100 folds for LGTK, 10 folds for BTK, and 100 folds for TPK) was mixed with $2.0 \mathrm{~mL}$ of phosphate buffer $(0.2 \mathrm{M}, \mathrm{pH} 6.60)$ and $2.0 \mathrm{~mL}$ of
$1 \% \mathrm{~K}_{3} \mathrm{Fe}(\mathrm{CN})_{6}$. The mixture was incubated at $50^{\circ} \mathrm{C}$ for $20 \mathrm{~min}$, after which $2.0 \mathrm{~mL}$ of $10 \%$ trichloroacetic acid (TCA) was added to the mixture and centrifuged at $4000 \mathrm{rpm}$ for $10 \mathrm{~min} ; 2 \mathrm{~mL}$ supernatant was then mixed with distilled water $(2.0 \mathrm{~mL})$ and $\mathrm{FeCl}_{3}(0.4 \mathrm{~mL}, 0.1 \%)$, and absorbance was measured at $700 \mathrm{~nm}$.

\subsection{Plate count method}

In order to enumerate the probiotics, diluted kombucha $(200 \mathrm{uL})$ prepared from low-cost green tea (LGTK) was spread on the surface of the plates containing the appropriate microorganism (Ma et al., 2008; Xie, 2011; Amoa-Awua et al., 2007; Vasek et al., 2013). All analyses were carried out in duplicate. The plates were subsequently incubated at $30^{\circ} \mathrm{C}$ for 36-48 h. The colonies that have grown were counted. Yeasts were enumerated on Yeast Extract Agar containing $100 \mathrm{mg} \mathrm{L}^{-1}$ oxytetracycline, $10 \mathrm{~g} \mathrm{~L}^{-1}$ yeast extract (Sangon Biotech (Shanghai), Ltd, Shanghai, China), $10 \mathrm{~g} \mathrm{~L}^{-1}$ peptone, $20 \mathrm{~g} \mathrm{~L}^{-1}$ glucose, and $20 \mathrm{~g} \mathrm{~L}^{-1}$ agar (Sangon Biotech (Shanghai), Ltd, Shanghai, China) in $100 \mathrm{~mL}$ distilled water. Acetic acid bacteria were enumerated on a medium containing $200 \mathrm{U} \mathrm{mL}^{-1}$ nystatin, $10 \mathrm{~g} \mathrm{~L}^{-1}$ yeast extract (Sangon Biotech (Shanghai), Ltd, Shanghai, China), $10 \mathrm{~g} \mathrm{~L}^{-1}$ glucose , 3\% absolute ethanol, $20 \mathrm{~g} \mathrm{~L}^{-1} \mathrm{CaCO}_{3}$, and $20 \mathrm{~g} \mathrm{~L}^{-1}$ agar (Sangon Biotech (Shanghai), Ltd, Shanghai, China) in $100 \mathrm{~mL}$ distilled water. Lactic acid bacteria were enumerated on MRS medium containing $200 \mathrm{U} \mathrm{mL}^{-1}$ nystatin, $10 \mathrm{~g} \mathrm{~L}^{-1}$ beef extract (Sangon Biotech (Shanghai), Ltd, Shanghai, China), $5 \mathrm{~g} \mathrm{~L}^{-1}$ yeast extract (Sangon Biotech (Shanghai), Ltd, Shanghai, China), $10 \mathrm{~g} \mathrm{~L}^{-1}$ peptone, $20 \mathrm{~g} \mathrm{~L}^{-1}$ glucose, $5 \mathrm{~g} \mathrm{~L}^{-1}$ $\mathrm{NaOAc}, 2 \mathrm{~g} \mathrm{~L}^{-1}$ ammoniumhydrogencitrate, $0.1 \%$ Tween-80, $2 \mathrm{~g} \mathrm{~L}^{-1} \mathrm{MgSO}_{4} \cdot 7 \mathrm{H}_{2} \mathrm{O}, 0.05 \mathrm{~g} \mathrm{~L}^{-1} \mathrm{MnSO}_{4} \cdot 4 \mathrm{H}_{2} \mathrm{O}$, and $2 \mathrm{~g} \mathrm{~L}^{-1} \mathrm{~K}_{2} \mathrm{HPO}_{4}$ and $20 \mathrm{~g} \mathrm{~L}^{-1}$ agar (Sangon Biotech (Shanghai), Ltd, Shanghai, China) in $100 \mathrm{~mL}$ distilled water.

\subsection{Statistical Analysis}

The results were expressed as mean \pm SD. Significance of differences was determined using the Duncan's multiple range test, and the computer software used for this study was Statistical Product and Service Solutions (SPSS), version 17.0, by International Business Machines Corporation.

\section{Results and discussion}

In order to demonstrate the antioxidant activity of kombucha prepared from low-cost green tea (LGTK), black tea (BTK), and tea powder (TPK), scavenging assays against 2,2-diphenyl-1-picrylhydrazyl (DPPH), superoxide anion, and hydroxyl radicals were used to evaluate free-radical scavenging abilities changes and the total reducing power. All analyses were carried out in duplicate after the sugared teas were fermented for $90 \mathrm{~h}$ followed by centrifugation at $10,000 \mathrm{rpm}$ for $10 \mathrm{~min}$. LGTK had the highest scavenging ability against DPPH, superoxide anions, and hydroxyl radical, while BTK had the highest reducing power. The free-radical scavenging activity values found are shown in Figure 1.

The scavenging abilities of hydroxyl radicals and DPPH were in descending order: LGTK > TPK > BTK. The DPPH scavenging ratio of LGTK reached $95.30 \%$. TPK had the lowest 


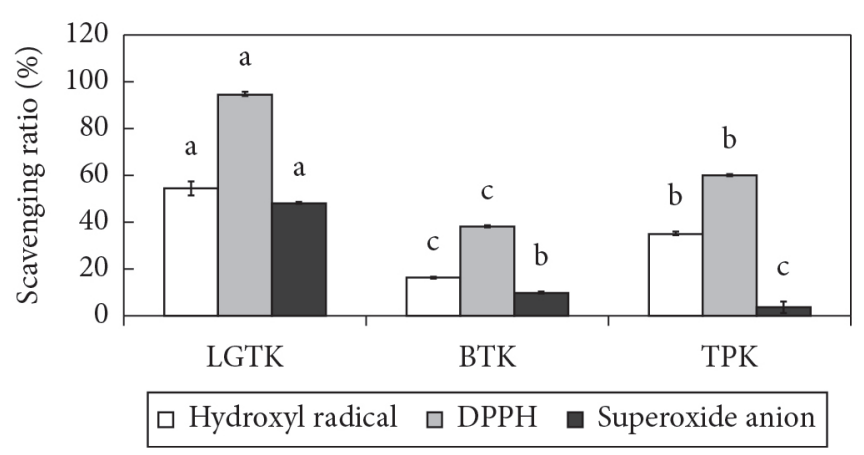

Figure 1. Antioxidant activities of kombucha. Data presented are the means of duplicate samples, and the error bars represent the standard deviations. All analyses were performed after the sugared teas were fermented for $90 \mathrm{~h}$ followed by centrifugation at 10,000 rpm for 10 $\min$. Means with different letters are significantly different $(\mathrm{p}<0.05)$. LGTK: low-cost green tea kombucha; BTK: black tea kombucha; TPK: tea powder kombucha.

superoxide anion scavenging ratio (3.8\%), while BTK had the lowest DPPH scavenging ratio, with the value of $38.7 \%$. Consistent with our results, Chu and Chen found that DPPH radical scavenging activities of eight BTK varied from $30 \%$ to $50 \%$ when investigating the effects of origin and fermentation time on the antioxidant activities of BTK (Chu \& Chen, 2006). The DPPH scavenging ratio of BTK increased to about $70 \%$ after fermenting for 15 days (Chu \& Chen, 2006). Among the samples of kombucha prepared from green tea, black tea, and tea manufacture waste analyzed, green tea kombucha showed higher DPPH scavenging ability $(88 \%)$ on $18^{\text {th }}$ day of fermentation (Jayabalan et al., 2008b). The effect of fermentation time on sensory and bioactive properties should be taken into account when preparing kombucha. Moreover, free-radical scavenging activities, the total reducing power of LGTK, BTK, and TPK was determined according to the method described by Yen \& Chen (1995). BTK had the highest total reducing power, as evidenced by an absorbance of 0.613 at $700 \mathrm{~nm}$, followed by LGTK and TPK (absorbance at $700 \mathrm{~nm}: 0.304$ and 0.111 , respectively). In a study on the preservation of kombucha tea-effect, Jayabalan et al. found that heat treatment at 60, 65, and $68{ }^{\circ} \mathrm{C}$ for $1 \mathrm{~min}$ led to a decrease in tea polyphenols and free radical scavenging properties during storage. It was thus suggested that heat treatment was not a suitable method for kombucha preservation (Jayabalan et al., 2008a).

In order to test the microbiological changes in low-cost green tea kombucha (LGTK) during storage, the LGTK samples were placed in a refrigerator at $4{ }^{\circ} \mathrm{C}$. The content of yeast, acetic acid bacteria (AAB), lactic acid bacteria (LAB), and total bacteria (TB) were determined every 2 days using the plate count method (Ma et al., 2008; Xie, 2011; Amoa-Awua et al., 2007; Vasek et al., 2013). Equivoluminal bacteria medium replaced kombucha in the control sample. After 90 hours of fermentation, the number of yeast, $\mathrm{AAB}, \mathrm{LAB}$, and $\mathrm{TB}$ in the low-cost green tea kombucha produced was $1.45 \times 10^{7}, 1.0 \times 10^{7}, 2.8 \times 10^{5}$, and $2.49 \times 10^{7} \mathrm{CFU} / \mathrm{mL}$, respectively. Microbial changes during the storage period of 14 days are shown in Figure 2. Overall, the

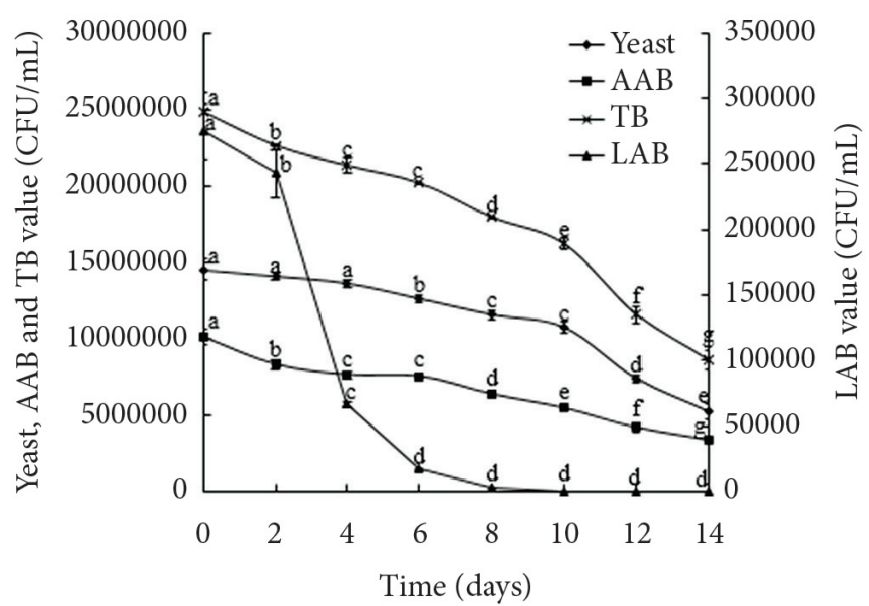

Figure 2. Kombucha bacteria survival during 14 days of refrigerated storage. Data presented are the means of duplicate samples, and the error bars represent the standard deviations. Means with different letters are significantly different $(\mathrm{p}<0.05)$. AAB: acetic acid bacteria; TB: total bacteria; LAB: lactic acid bacteria.

number of $\mathrm{AAB}$ moderately decreased from $9.3 \times 10^{6} \mathrm{CFU} / \mathrm{mL}$ on the first day to $3.4 \times 10^{6} \mathrm{CFU} / \mathrm{mL}$ on $14^{\text {th }}$ day. The amount of yeast decreased slightly on the first days, followed by a quick decrease after 10 days of storage. The survival rate of yeast and $\mathrm{AAB}$ on $10^{\text {th }}$ day was $73.97 \%$ and $54.09 \%$, respectively. In contrast, the amount of LAB significantly decreased after 2 days of storage. The number of $\mathrm{LAB}$ was $2.7 \times 10^{3} \mathrm{CFU} / \mathrm{mL}$ on $8^{\text {th }}$ day, corresponding to a survival rate of $0.98 \%$. In a study on the viability of two LABs in yogurt stored at $5{ }^{\circ} \mathrm{C}$ at lower $\mathrm{pH}$ values (3.5), the decrease in cell counts of $L$. acidophilus was $2.5 \log$ orders after 1 week, which is significantly higher than that at higher $\mathrm{pH}$ values ( $\mathrm{pH} 4.5,5.5$ and 6.5.) (Vinderola et al., 2000). The low $\mathrm{pH}$ value (3.15) of LGTK may be due to the rapid decrease of $L A B$ in kombucha. In addition, it has been reported that the yeast enhanced the viability of $L$. rhamnosus at $30{ }^{\circ} \mathrm{C}$ but not at $12{ }^{\circ} \mathrm{C}$ (Suharja et al., 2012). The low temperature $\left(4^{\circ} \mathrm{C}\right)$ used in the present study may have reduced the viabilityenhancing effect of the yeast against LAB.

\section{Conclusions}

The present study compared the scavenging abilities against 2,2-diphenyl-1-picrylhydrazyl (DPPH), superoxide anions, and hydroxyl radical, as well as the total reducing power of kombucha prepared from low-cost green tea (LGTK), black tea (BTK), and tea powder (TPK). The scavenging abilities of hydroxyl radicals and DPPH were in descending order: LGTK $>$ TPK > BTK. Producing antioxidant kombucha by a quick fermentation of low-cost green tea can be ideal and economical. When storing low-cost green tea kombucha (LGTK) under refrigeration at $4{ }^{\circ} \mathrm{C}$, acetic acid bacteria number moderately decreased, while the number of lactic acid bacteria significantly decreased during storage of 14 days. A study on increasing lactic acid bacteria in LGTK during storage is being carried out in order to produce LGTK as a multifunctional product. 


\section{Acknowledgements}

The authors gratefully acknowledge the financial support by the Natural Science Foundation of Fujian Province, China (Grant No. 2011J01218), the Research Foundation for the ObjectiveOriented Project of Fuzhou University (No. XRC1164), and the Natural Science Foundation of Fujian Province, China (Grant No. 2012J05056). The authors thank Priscila Duarte for the kind help improving presentation of the article.

\section{References}

Chen, C., \& Liu, B. Y. (2000). Changes in major components of tea fungus metabolites during prolonged fermentation. Journal of Applied Microbiology, 89(5), 834-839. http://dx.doi.org/10.1046/ j.1365-2672.2000.01188.x

Greenwalt, C. J., Steinkraus, K. H., \& Ledford, R. A. (2000). Kombucha, the fermented tea: microbiology, composition, and claimed health effects. Journal of Food Protection, 63(7), 976-981.

Malbasa, R., Loncar, E., \& Djuric, M. (2008). Comparison of the products of Kombucha fermentation on sucrose and molasses. Food Chemistry, 106(3), 1039-1045. http://dx.doi.org/10.1016/j. foodchem.2007.07.020

Chu, S., \& Chen, C. (2006). Effects of origins and fermentation time on the antioxidant activities of kombucha. Food Chemistry, 98(3), 502-507. http://dx.doi.org/10.1016/j.foodchem.2005.05.080

Malbasa, R., Loncar, E., Vitas, J., \& Canadanovic-Brunet, J. M. (2011). Influence of starter cultures on the antioxidant activity of kombucha beverage. Food Chemistry, 127(4), 1727-1731. http://dx.doi. org/10.1016/j.foodchem.2011.02.048

Ma, C., Lin, J., Yang, M., \& Liu, Z. (2008). Optimization of technical conditions in the fermentation of kombucha. Food Research and Development, 29(3), 36-38.

Xie, F. (2011). Study on the functional tea beverages fermented with low-grade tea (Master's thesis). Fuzhou University.

Aloulou, A., Hamden, K., Elloumi, D., Ali, M. B., Hargafi, K., Jaouadi, B., Ayadi, F., Elfeki, A., \& Ammar, E. (2012). Hypoglycemic and antilipidemic properties of kombucha in alloxan-induced diabetic rats. BMC Complementary and Alternative Medicine, 12, 12-63. http://dx.doi.org/10.1186/1472-6882-12-63

Ilicic, M., Kanuric, K., Milanovic, S., Loncar, E. S., Djuric, M. S., \& Malbasa, R. V. (2012). Lactose fermentation by Kombucha-a process to obtain new milk-based beverages. Romanian Biotechnological Letters, 17(1), 7013-7021.

Yang, Z., Ji, B., Zhou, F., Li, B., Luo, Y., Yang, L., \& Li, T. (2009). Hypocholesterolaemic and antioxidant effects of kombucha tea in high-cholesterol fed mice. Journal of the Science of Food and Agriculture, 89(1), 150-156. http://dx.doi.org/10.1002/jsfa.3422

Greenwalt, C., Ledford, R., \& Steinkraus, K. (1998). Determination and characterization of the antimicrobial activity of the fermented tea kombucha. LWT-Food Science and Technology, 31(3), 291-296. http://dx.doi.org/10.1006/fstl.1997.0354
Jayabalan, R., Marimuthu, S., \& Swaminathan, K. (2007). Changes in content of organic acids and tea polyphenols during kombucha fermentation. Food Chemistry, 102(1), 392-398. http://dx.doi. org/10.1016/j.foodchem.2006.05.032

Jayabalan, R., Marimuthu, S., Thangaraj, P., Sathishkumar, M., Binupriya, A. R., Swaminathan, K., \& Yun, S. E. (2008a). Preservation of kombucha tea-effect of temperature on tea components and free radical scavenging properties. Journal of Agricultural and Food Chemistry, 56(19), 9064-9071. http://dx.doi.org/10.1021/jf8020893

Yang, Z., Zhou, F., Ji, B., Li, B., Luo, Y., Yang, L., \& Li, T. (2010). Symbiosis between microorganisms from kombucha and kefir: Potential significance to the enhancement of kombucha function. Applied Biochemistry and Biotechnology, 160(2), 446-455. http:// dx.doi.org/10.1007/s12010-008-8361-6

Marques, M. R., Paz, D. D., Batista, L. P. R., Barbosa, C. O., Araújo, M. A. M., \& Moreira-Araujo, R. S. R. (2012). An in vitro analysis of the total phenolic content, antioxidant power, physical, physicochemical, and chemical composition of Terminalia Catappa Linn fruits. Ciência e Tecnologia de Alimentos, 32(1), 209-213. http:// dx.doi.org/10.1590/S0101-20612012005000023

Vissotto, L. C., Rodrigues, E., Chisté, R. C., Benassi, M. T., \& Mercadante, A. Z. (2013). Correlation, by multivariate statistical analysis, between the scavenging capacity against reactive oxygen species and the bioactive compounds from frozen fruit pulps. Ciência e Tecnologia de Alimentos, 33(Supl. 1), 57-65.

Li, X., Lin, J., Gao, Y., Han, W., \& Chen, D. (2012). Antioxidant activity and mechanism of Rhizoma Cimicifugae. Chemistry Central Journal, 6, 140-149. http://dx.doi.org/10.1186/1752-153X-6-140

Yen, G., \& Chen, H. (1995). Antioxidant activity of various tea extracts in relation to their antimutagenity. Journal of Agricultural and Food Chemistry, 43(1), 27-32. http://dx.doi.org/10.1021/jf00049a007

Amoa-Awua, W. K., Sampson, E., \& Tano-Debrah, K. (2007). Growth of yeasts, lactic and acetic acid bacteria in palm wine during tapping and fermentation from felled oil palm (Elaeis guineensis) in Ghana. Journal of Applied Microbiology, 102(2), 599-606. http://dx.doi. org/10.1111/j.1365-2672.2006.03074.x

Vasek, O. M., Mazza, S. M., \& Giori, G. S. (2013). Physicochemical and microbiological evaluation of corrientes artisanal cheese during ripening. Food Science and Technology, 33(1), 151-160. http://dx.doi. org/10.1590/S0101-20612013005000021

Jayabalan, R., Subathradevi, P., Marimuthu, S., Sathishkumar, M., \& Swaminathan, K. (2008b). Changes in free-radical scavenging ability of kombucha tea during fermentation. Food Chemistry, 109, 227234. http://dx.doi.org/10.1016/j.foodchem.2007.12.037

Vinderola, C. G., Bailo, N., \& Reinheimer, J. A. (2000). Survival of probiotic microflora in Argentinian yoghurts during refrigerated storage. Food Research International, 33(2), 97-102. http://dx.doi. org/10.1016/S0963-9969(00)00011-9

Suharja, A. S., Henriksson, A., \& Liu, S. Q. (2012). Impact of saccharomyces cerevisiae on viability of probiotic lactobacillus rhamnosus in fermented milk under ambient conditions. Journal of Food Processing and Preservation, 10, 1-12. 